\title{
Association between tonsillectomy, adenoidectomy, and appendicitis
}

\author{
J. C. Andreu Ballester, F. Ballester ${ }^{1}$, E. Colomer Rubio and M. Millán Scheiding² \\ Department of Emergency Medicine. Hospital Arnau de Vilanova. ${ }^{1}$ Unit of Epidemiology and Statistics. Escuela \\ Valenciana de Estudios para la Salud. Conselleria de Sanidad. Generalitat Valenciana. ${ }^{2}$ Service of Surgery. Hospital \\ Arnau de Vilanova. Valencia, Spain
}

\begin{abstract}
Introduction: tonsillectomy, with or without adenoidectomy, is one of the most frequent surgical procedures generally performed, especially in young patients. Several studies suggest that there is a relationship between tonsillectomy and altered MALT immune system.

Objective: to examine the possible association between tonsillectomy or adenoidectomy and the risk of subsequent appendicitis.

Material and method: a cross-sectional study was performed in 650 patients admitted to the emergency department of a general hospital in Valencia, Spain. Previous history of tonsillectomy and/or adenoidectomy was related to a history of appendectomy. A descriptive study and an analysis of the relationship between previous operations and appendicitis was performed. A multivariable analysis controlled for age and sex was also performed, including the possible interaction of the gender variable. The independent effect of each of the procedures (tonsillectomy, adenoidectomy) was tested.

Results: the $25.5 \%$ of patients had undergone tonsillectomy and $11.5 \%$ adenoidectomy; $17.5 \%$ had had an appendectomy. On average, women were operated on more frequently than men. In the bivariate analysis, both tonsillectomy and adenoidectomy were significantly associated with subsequent appendectomy. In the multivariate analysis, this association was only maintained for tonsillectomy (OR: 3.23; 95\% CI: 2.11-4.94). A stratified analysis controlling for sex showed a modification of this effect, with a higher association in women (OR: 5.20; 95\% CI: 2.91-9.28) than in men (OR: 1.74; 95\% CI: 0.90-3.39).

Conclusions: a clear association has been found, especially in women, between previous tonsillectomy and subsequent acute appendicitis. Due to a lack of data on acute appendicitis there should be further studies to explain the findings of this study, as this could be the first described risk factor of acute appendicitis.
\end{abstract}

Key words: Tonsillectomy. Adenoidectomy. Appendicitis. MALT system.

Recibido: 11-03-04.

Aceptado: 01-06-04.

Correspondencia: Juan Carlos Andreu Ballester. C/ Juan Ramón Jiménez, 29-14a 46006 Valencia. Tel.: 963339 473. e-mail: jcandreu@ono.com
Andreu Ballester JC, Ballester F, Colomer Rubio E, Millán Scheiding M. Association between tonsillectomy, adenoidectomy, and appendicitis. Rev Esp Enferm Dig 2005; 97: 179-186.

\section{INTRODUCTION}

Tonsillectomy and adenoidectomy are two of the most frequently performed surgical procedures in general, and are very common in children and adolescents. Ogra observed that after tonsillectomy there was a reduced production of $\operatorname{IgA}$ against the oral antipolio vaccination in children (1).

Tonsillectomy has also been associated with Hodgkin's disease, especially in adolescents under 12 years of age (2). A study in Israel found an association only in mixed cellularity cases, not in other types (3). Other studies do not corroborate these findings (4). Mueller found a higher relative risk in older patients (5).

Some authors have not found changes in levels of immunoglobulins after tonsillectomy (6). Brandtzaeg described a lower level of secretory IgA after tonsillectomy and adenoidectomy (7). Ostergaard observed lower levels of IgA in children with atopic diseases and previous tonsillectomy (8). Cantani et al. also found low levels of IgA in children one month after tonsillectomy, and recommended their determination before and after surgery due to the possibility of subsequent disorders (9); another study confirmed these findings in salivary $\operatorname{IgA}$ levels (10). Friday et al. found low levels of IgG in children 30 months after tonsillectomy and/or adenoidectomy (11). An association has also been found between tonsillectomy and Crohn's disease, especially terminal-ileum Crohn's disease $(12,13)$.

Based on all these findings, there seems to be some type of relationship between tonsillectomy and changes in the MALT system of the digestive tract. However, 
there does not seem to be any previous studies on the relationship between this procedure and another of the more frequent surgical removals of an organ included in the MALT system, the appendix. The appendix may substitute the loss of another MALT organ (tonsils) and become more frequently inflamed in infection. On the other hand, there are no clear risk factors described for acute appendicitis.

The purpose of this study was to examine the possible association between tonsillectomy or adenoidectomy and the risk of subsequent acute appendicitis.

\section{PATIENTS AND METHODS}

A cross-sectional study was performed including randomly selected patients admitted to the Emergency Department of Arnau de Vilanova Hospital, which serves a population of approximately 275,000 patients. A survey was performed, completed by the physician in front of the patient, to investigate previous tonsillectomy, adenoidectomy and appendectomy, and at what age they had been performed. The operation was confirmed by physical examination. Patients who were not sure of their responses were eliminated, as well as patients who could not respond. A total of 650 patients were selected.

The following variables were recorded: appendectomy (AP), age, sex, tonsillectomy (AM), age of tonsillectomy, adenoidectomy (AD), age of adenoidectomy, age of appendectomy, and interval between operations (age). Categorical variables included sex, AP, AM, AD; the rest were continuous variables.

\section{Statistical analysis}

All of the data were introduced in a database and analyzed using two statistical programs: SPSS v. 10 (14) and EPIINFO (15). For descriptive statistics, absolute and relative rates were used for categorical variables, and mean, median, standard deviation and range were used for continuous variables. Contingency tables were constructed to compare the frequency of surgical intervention on lymphatic organs in men and women, and the association of the sex variable; each of the operations was contrasted using a two- tailed Fischer's exact test.

Normal distribution was confirmed in continuous variables (age, age at which procedures occurred, and intervals between procedures) by sex using the KolmogorovSmirnov test with Killiefors correction. When a normal distribution was assumed, a Student's t-test was used to compare the means of continuous variables classified according to sex. If normality was not assumed, a non-parametric Mann-Whitney test was used.

To calculate the association measurements between variables, we considered appendectomy to be the response variable. Tonsillectomy and adenoidectomy were considered explanatory variables. The sex and age of the patient were included in the models as control variables. The relative importance of each of these variables was calculated using multivariate models of logistic regression including variables that showed statistical significance $(p<0.20)$. The existence of differences in the effect of explanatory variables by sex was investigated by including the interaction terms within the models and then studying their statistical significance. If an interaction was found, a stratified analysis by sex was performed.

\section{RESULTS}

The prevalence of each of the surgical procedures in general and according to sex may be observed in table I. No significant differences were found. There is a difference of four years of age between surveyed men and women. There were no significant differences in frequency of operations, except for prevalence of appendectomy $(\mathrm{p}=0.06)$; this was more frequent in women $(20.4 \mathrm{vs}$. $14.7 \%$ in men). Table II shows the means and medians of the different ages at which surgeries were performed, as well as the intervals between tonsillectomy and/or adenoidectomy and appendectomy. Figure 1 shows the percentages of patients in which each operation was performed, following the distribution by age quartiles. Table III compares the average ages of appendectomy depending on the existence of a previous tonsillectomy or adenoidectomy. No significant differences were found. There were significant differences in the average age at

Table I. Age of the study population and procedures performed*

\begin{tabular}{lcccc}
\hline & Total (650) & Men (326) & Women (324) & Sig. \\
\hline Age & 45.62 & 43.73 & 47.52 & 0.012 \\
Tonsillectomy & $166(25.5 \%)$ & $78(23.9 \%)$ & $88(27.9 \%)$ & 0.369 \\
Adenoidectomy & $75(11.5 \%)$ & $39(12 \%)$ & $36(11.1 \%)$ & 0.806 \\
Appendectomy & $114(17.5 \%)$ & $48(14.7 \%)$ & $66(20.4 \%)$ & 0.064 \\
\hline
\end{tabular}

*Number of operated patients (percentage).

Table II. Average age

\begin{tabular}{lccccc}
\hline & Age & Age AM & Age AD & Age AP & $\begin{array}{c}\text { Interval between } \\
\text { AM and/or AD and } \\
\text { AP (years) }\end{array}$ \\
\hline $\mathrm{n}$ & 650 & 165 & 74 & 113 & 53 \\
Minimum & 9 & 2 & 1 & 6 & 1 \\
Maximum & 88 & 50 & 50 & 79 & 40 \\
Average & 45.62 & 9.92 & 8.64 & 22.01 & 12.38 \\
Median & 45 & 6 & 6 & 20.50 & 16.50 \\
Stand. dev. & 19.22 & 7.63 & 7.40 & 13.03 & 10.23
\end{tabular}




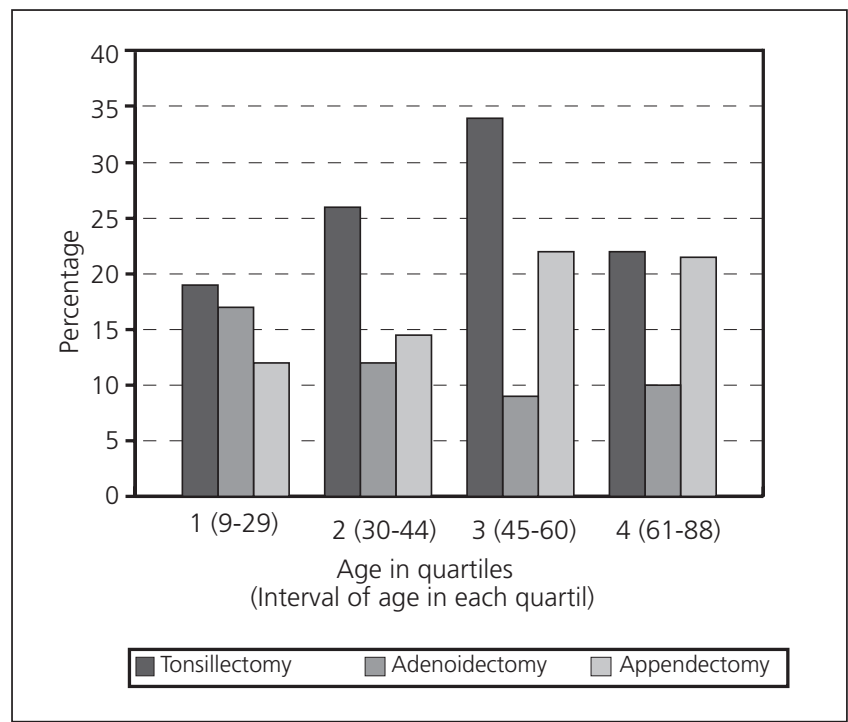

Fig. 1.- Percentage for each surgical procedure according to age. Distribution in quartiles.

Porcentaje de cada una de las intervenciones quirúrgicas a estudio según la edad. Distribución por cuartiles.

Table III. Average age (and $95 \%$ confidence interval) at appendectomy according to previous tonsillectomy (AM) or adenoidectomy (AD)

\begin{tabular}{lcc}
\hline Procedure & Average age AP (years) & Sig. \\
\hline AM & $21.38(18.41-24.35)$ & $\mathrm{p}=0.640$ \\
No AM & $22.54(18.75-26.34)$ & \\
AD & $25.27(19.60-30.94)$ & $\mathrm{p}=0.192$ \\
No AD & $21.22(18.50-23.93)$ & \\
\hline
\end{tabular}

appendectomy according to sex (Table IIIa) - the operation was performed earlier in women than in men $(19.5$ vs. 25.5 years in men).

The average time between tonsillectomy-adenoidectomy and appendicitis (Table IIIb) is 12.38 years (95\% confidence interval: 9.56-15.20). If we compare time intervals according to sex, these are 16.87 years in men $(95 \%$ CI: 9.71-24.03) and 10.61 years in women $(95 \% \mathrm{CI}$ : 7.81-13.40) $(\mathrm{p}=0.099)$.

Tables IVa and IVb show the analysis of a simple association between tonsillectomy or adenoidectomy and subsequent appendectomy. Our results indicate a significant positive association; patients with a previous tonsillectomy exhibit 3.25 times more probabilities of being operated on subsequently for acute appendicitis: OR: 3.25 (95\% CI; 2.13-4.96). The association between adenoidectomy and appendectomy was also significant: OR: 2.35 (95\% CI; 1.37-4.03).

After stratifying according to sex, it may be observed that the association between tonsillectomy and appendectomy in men decreases, and statistical significance disappears: OR 1.74 (95\% CI: 0.90-3.38), while in women the association is stronger: OR: 5.18 (95\% CI: 2.92-9.20).
Table Illa. Average age (and $95 \%$ confidence interval) at appendectomy according to sex

\begin{tabular}{lcc}
\hline Sex & Average age $A P$ & Sig. \\
\hline Men & $25.49(20.63-30.35)$ & $p=0.029$ \\
Women & $19.53(17.28-21.78)$ & \\
\hline
\end{tabular}

Table IIlb. Average interval between procedures (and $95 \%$ confidence interval) in years between AM-AD and AP

\begin{tabular}{llc}
\hline & & Sig. \\
\hline Global & $12.38(9.56-15.20)$ & $\mathrm{p}=0.099$ \\
Men & $16.87(9.71-24.03)$ & \\
Women & $10.61(7.81-13.40)$ & \\
\hline
\end{tabular}

Table IVa. Association between tonsillectomy (AM) and appendectomy (AP)

\begin{tabular}{lccc}
\hline & AP & No AP & Total \\
\hline AM & $53(31.9 \%)$ & $113(68.1 \%)$ & 166 \\
No AM & $61(12.6 \%)$ & $423(87.4 \%)$ & 484 \\
& $114(17.5 \%)$ & $536(82.5 \%)$ & 650 \\
\hline$P=<0.0000001 .0 R \cdot 3.25$. ICOR $95 \% \cdot 2.13-4.96$ &
\end{tabular}

$p=<0.0000001$. OR: 3.25. ICOR 95\%: $2.13-4.96$

Table IVb. Association between adenoidectomy (AD) and appendectomy (AP)

\begin{tabular}{lccc}
\hline & $A P$ & No $A P$ & Total \\
\hline AD & $23(30.7 \%)$ & $52(69.3 \%)$ & 75 \\
No AD & $91(15.8 \%)$ & $484(84.2 \%)$ & 575 \\
& $114(17.5 \%)$ & $536(82.5 \%)$ & 650 \\
\hline
\end{tabular}

$\mathrm{p}=<0.002$. OR: 2.35. ICOR95\%: $1.37-4.04$

On the contrary, the association between adenoidectomy and appendectomy was stronger in men: OR: 3.10 (95\% CI: 1.44-6.66) than in women: OR: 1.86 (95\% CI: 0.864.02).

A multivariate analysis controlling for age and sex showed similar results. The odds ratio for the association between tonsillectomy and appendicitis was 3.23 (95\% CI: 2.11-4.94), and between adenoidectomy and appendicitis 2.57 (95\% CI: 1.48-4.46). However, after controlling the variable tonsillectomy, the association between appendicitis and adenoidectomy disappears (OR: 1.26; 95\% CI 0.67-2.38); tonsillectomy remains significant and without major changes (OR: 2.97; 95\% CI 1.82-4.82).

The study of possible interactions between variables showed a significant modification of effect $(p=0.013)$ between tonsillectomy and sex. A stratified analysis controlling for age showed a result similar to that of the simple analysis: OR 1.74 (95\% CI 0.90-3.39) for men, and 5.20 (95\% CI 2.91-9.28) for women; this has been presented previously (16). 


\section{DISCUSSION}

More than a quarter of patients admitted to an Emergency Department within a General Hospital in Valencia have had a tonsillectomy, and over $11 \%$ have had an adenoidectomy; $17.5 \%$ had an appendectomy. There were no significant differences between sexes with respect to having had a previous tonsillectomy or appendectomy, but results suggest a higher prevalence of appendectomy in women. These prevalences in our sample do not differ from those previously estimated by the National Health Institute (INSALUD) or those described in a study performed in Madrid, with prevalences of 18,17 and $20 \%$, respectively (17). However, in our case the prevalence of tonsillectomy was lower than in other studies, the estimations of INSALUD $(30 \%)$, and those of the study by López Ramos et al. in Madrid (17). In this study, the relation between MALTectomy and inflammatory bowel disease is analyzed. In the population-based control groups, the prevalence of tonsillectomy was 36 to $39 \%$. The age of these control subjects was similar to that of ours (42 years old), which suggests that the performance of these procedures has been different in different areas of Spain.

On average, women are operated on for acute appendicitis at an earlier age than men are. We have also found differences in time between operations between men (16.9 years) and women (10.6), which seem logical and coincides with the fact that women are operated on at an earlier age than men.

A clear association was found between tonsillectomy and acute appendicitis. This association is not as evident (multivariate analysis) between adenoidectomy and appendicitis. There is also an important difference in the association between tonsillectomy and appendicitis in men and women. An explanation for these differences is not clear, but some studies indicate differences in the development of the immune system related to the $\mathrm{X}$ chromosome (18) or estrogens (19).

The study population is considered representative of the reference population. In the Valencian Community the health system is of universal coverage, and the number of persons with private insurance is around 10\%. Furthermore, in acute cases, most people go to the Emergency Departments of public hospitals. Finally, the percentage of people presenting to Emergency Departments not in their reference area is low. In a previous study, only $3 \%$ of people seen in an Emergency Department in Valencia came from a different reference area (20).

The main limitation of the present study is its design; it is a cross-sectional study where information was obtained from data reported by patients. This fact could be biased by memory failure, especially in elderly patients or when surgery was performed many years before the study; we have tried to avoid this bias by eliminating patients who were not sure of their answers on inquiry. There is always a percentage of blank laparotomies, which oscillates between 10 and $15 \%$ depending on the author (21), which is a bias that may be even higher in women (14-35\%) (22-24) versus men; however, should it modify the results, which would not change the association.

The explanation of these findings opens a large possibility of different hypotheses to be corroborated in new studies. A first proposition would be that tonsillectomy produces an important deficiency in lymphoid tissue, which forces the remaining tissue (appendix) to make up for this deficiency in response to incoming pathogens, thus making it more likely to become inflamed or infected. Another possibility would be that there is a population with a higher predisposition (higher immune reactivity) to hypertrophy. This higher immune reactivity could even be abnormal, with a higher predisposition to diseases such as Crohn's and Hodgkin's diseases.

In younger age groups the frequency of tonsillectomy and appendectomy are similar. However, as age increases, there is a drastic fall in the amount of people reporting having had an adenoidectomy. This fact could reflect the evolution of the practice of these two procedures (in more recent years they have been performed simultaneously, but years ago this was not the case), or it could reflect forgetfulness of the procedure in surveyed patients. In our opinion, the first possibility explains the contradiction more strongly. In case that there had been a bias of misclassification in the diagnosis (persons who had had an adenoidectomy but said they had not), this bias may have affected the association between adenoidectomy and appendicitis.

Due to the aforementioned limitations and the possible explanations of these results, it would be interesting that more studies be performed to add information on the findings of this study; this could be one of the first risk factors described for acute appendicitis.

\section{REFERENCES}

1. Ogra PL. Effect of tonsillectomy and adenoidectomy on nasopharyngeal antibody response to poliovirus. N Engl J Med 1971; 284: 59-64.

2. Liaw KL, Adami J, Gridley G, et al. Risk of Hodgkin's disease subsequent to tonsillectomy: a population-based cohort study in Sweden. Int J Cancer 1997; 72: 711-3.

3. Abramson JH, Pridan H, Sacks MI, Avitzour M, Peritz E, et al. A case-control study of Hodgkin's disease in Israel. J Natl Cancer Inst 1978; 61: 307-14.

4. Gledovic Z, Radovanovic Z. History of tonsillectomy and appendectomy in Hodgkin's disease. Eur J Epidemiol 1991; 7: 612-5.

5. Mueller N, Swanson GM, Hsieh CC, Cole P. Tonsillectomy and Hodgkin's disease: results from companion population-based studies. J Natl Cancer Inst 1987; 78: 1-5.

6. Paulussen C, Claes J, Claes G, Dorissen M, et al. Adenoids and tonsils, indications for surgery and immunological consequences of surgery. Acta Otorhinolaryngol Belg 2000; 54: 403-8.

7. Brandtzaeg P. The B-cell development in tonsillar lymphoid follicles. Acta Otolaryngol Suppl 1996; 523: 55-9.

8. Ostergaard PA. B- and T-cells and intracellular Ig-synthesis of peripheral lymphocytes in children with asthma and/or previous adenotonsillectomy. Acta Pathol Microbiol Scand [C] 1977; 85C: 454-62.

9. Cantani A, Bellioni P, Salvinelli F, Businco L. Serum immunoglobulins and secretory IgA deficiency in tonsillectomized children. Ann Allergy 1986; 57: 413-6. 
10. D' Amelio R, Palmisano L, Le Moli S, Seminara R, Aiuti F. Serum and salivary IgA levels in normal subjects: comparison between tonsillectomized and non-tonsillectomized subjects. Int Arch Allergy Appl Immunol 1982; 68: 256-9.

11. Friday GA Jr, Paradise JL, Rabin BS, Colborm DK, Taylor FH. Serum immunoglobulin changes in relation to tonsil and adenoid surgery. Ann Allergy 1992; 69: 225-30.

12. Koutroubakis IE, Vlachonikolis IG, Kapsoritakis A, Spanoudakis S, Roussomoustakaki N, Mouzas IA, et al. Appendectomy, tonsillectomy, and risk of inflammatory bowel disease: casecontrolled study in Crete. Dis Colon Rectim 1999; 42: 225-30.

13. Maté-Jiménez J, Correa-Están JA, PérezMiranda M, et al. Tonsillectomy and inflammatory bowel disease location. Eur J Gastroenterol Hepatol 1996; 8: 1185-8.

14. SPSS for Windows. Release 10. Chicago: SPSS Inc, 2000.

15. 15. Epi Info Versión 6.04, Geneva: WHO, 1997.

16. Andreu-Ballester JC, Colomer Rubio E, Millán Scheiding M, Ballester F. Tonsillectomy and risk of acute appendicitis. Am J Gastroenterol 2003; 98: 2806-7.

17. López Ramos D, Gabriel R, Cantero Perona J, Moreno Otero R, Fernández Bermejo M, MatéJiménez J. Asociación de MALTectomía (apendectomía y apendicetomía) con la enfermedad inflamatoria intestinal: estudio familiar. Rev Esp Enferm Dig 2001; 93: 303-8.
18. Eskola J, Nurmi T, Ruuskanen O. Defective B cell function associated with inherited interstitial deletion of the short arm of the $\mathrm{X}$ chromosome. J Immunol 1983; 131: 1218-21.

19. Medina KL, Strasser A, Kincade PW. Estrogen influences the differentiation, proliferation, and survival of early B-lineage precursors. Blood 2000; 95: 2059-67.

20. Ballester F, Pérez-Hoyos S, Rivera ML, Merelles T, Tenias JM, Soriaro JB, et al. Patrones de frecuentación y factores asociados al ingreso en el hospital de las urgencias hospitalarias por asma y por enfermedad pulmonar obstructiva crónica. Archivos de Bronconeumología 1999; 35: 20-6.

21. Flum DR, Morris A, Koepsell T, Dellinger EP. Has misdiagnosis of appendicitis decreased over time?: a population-based analysis. JAMA 2001; 286: 174853 .

22. Borgstein PJ, Gordijn RV, Eijsbouts QAJ, Cuesta MA. Acute appendicitis: a clear-cut case in men, a guessing game in women. Surg Endosc 1997; 11: 923-7.

23. Cox MR, McCall JL, Padbury RTA, Wilson TG, Wattchow DA, Toouli J. Laparoscopic surgery in women with a clinical diagnosis of acute appendicitis. Med J Aust 1995; 162: 130-2.

24. Flum DR, Koepsell T. The clinical and economic correlates of misdiagnosed appendicitis: nationwide analysis. Arch Surg 2002; 137: 799-804. 